\title{
Evaluation of Acute and Chronic Effects of D-Galactose on Memory and Learning in Wistar Rats
}

\author{
Bharti Chogtu, Avinash Arivazhahan, Sushil Kiran Kunder, Amod Tilak, Ravi Sori, Amruta Tripathy \\ Department of Pharmacology, Kasturba Medical College, Manipal University, Manipal, India
}

\begin{abstract}
Objective: D-galactose has been commonly used in rodent models to induce accelerated effects of aging, including those on learning, memory, and muscular tone and coordination. This is normally seen on chronic administration of D-galactose. However, there is minimal suggestive evidence on the short-term effects of the same. The aim of the study was to study the acute and chronic effects of D-galactose on learning and memory in Wistar rats.

Methods: Twenty four male Wistar rats were randomly assigned to the control, standard (rivastigmine), oral D-galactose $(200 \mathrm{mg} / \mathrm{kg} /$ day $)$ and subcutaneous D-galactose $(200 \mathrm{mg} / \mathrm{kg} /$ day $)$ for a total duration of 8 weeks. Effects on learning and memory were assessed at 2 weeks, 4 weeks and 8 weeks by Morris water maze model and passive avoidance testing.

Results: Both oral and subcutaneous D-galactose showed positive effects on learning and memory on acute dosing, whereas this beneficial effect was lost during chronic dosing.

Conclusion: Short-term administration of D-galactose showed positive effects, while long-term administration nullified these effects.
\end{abstract}

KEY WORDS: Morris water maze; Passive avoidance; Rivastigmine; Alzheimer's disease.

\section{INTRODUCTION}

D-galactose (D-gal) is a physiological nutrient that is chemically a reducing sugar. ${ }^{1)}$ It is found in abundance in milk, vegetables and fruits. ${ }^{2)} \mathrm{D}$-gal interacts with various free amines in the protein architecture via non-enzymatic glycation, resulting in the generation of advanced glycation products. This results in the generation of reactive oxygen species (ROS). Also, excessive levels of D-gal in the body (either due to increased intake or decreased metabolism) may lead to the formation of various ROS, chiefly through oxidative metabolism, and additionally through the secondary glycation pathway. ${ }^{3)}$ ROS and advanced glycation products have been implicated in several age-related diseases like Alzheimer's disease, dia-

Received: January 2, 2017 / Revised: January 31, 2017

Accepted: March 23, 2017

Address for correspondence: Bharti Chogtu, MD

Department of Pharmacology, Kasturba Medical College,

Manipal University, Manipal 576104, India

Tel: +91-820-2922365

E-mail: bharti.magazine@manipal.edu

ORCID: https://orcid.org/0000-0003-2615-9928 betes mellitus, cancers and amyotrophic lateral sclerosis, etc. ${ }^{4)}$

Since D-gal induces the generation of these advanced glycation products and ROS, it is commonly employed as a model to enhance aging in rodents, thereby finding a place in rodent models for Alzheimer's disease and other memory impairment disorders. Most of the studies that are currently available in the accessible literature mention that D-gal can successfully be used as a rodent model, when used subcutaneously or intraperitoneally. However, a few studies have shown that oral administration of D-gal is ironically protective against age-related changes. ${ }^{4,5)}$

Similarly, the temporal associations of these effects with the administration of D-gal are unclear. While most authors have mentioned that chronic administration of D-gal can lead to impairment of learning and memory in rodents, the acute effects of the sugar are not wellestablished. A few studies have shown that this is not a standard model, as these changes produced are not consistent across all species and ages. ${ }^{6}$ )

Rivastigmine, a cholinesterase inhibitor has a comparatively selective action on the enzyme in brain when

(ㄷ) This is an Open-Access article distributed under the terms of the Creative Commons Attribution Non-Commercial License (http://creativecommons.org/licenses/by-nc/4.0) which permits unrestricted non-commercial use, distribution, and reproduction in any medium, provided the original work is properly cited. 
compared to skeletal muscle and heart. Its role in memory can be attributed to cholinesterase inhibition in hippocampus and cortex, thus preventing neuronal damage and enhancing cholinergic transmission, culminating in an increase in memory and retention. A study has shown that rivastigmine at a dose of $0.5-2.5 \mathrm{mg} / \mathrm{kg}$ reduced the effects of scopolamine on working memory. ${ }^{7,8)}$

Hence, the current study was planned to evaluate the acute and chronic effects of D-gal on rodents, when administered through two different routes: subcutaneous and oral, and comparing the effects with a control group and a standard group treated with rivastigmine.

The aim of the current study was to evaluate the acute and chronic effects of D-gal on memory and learning in Wistar rats using two models: Morris water maze and passive avoidance test, at 2 weeks, 4 weeks and 8 weeks.

\section{METHODS}

\section{Animal Selection and Handling}

Twenty four male Wistar rats, weighing between 150 and $200 \mathrm{~g}$, were acquired from the Central Animal Research Facility, Manipal University. The rats were randomly assigned to one of the four groups, and their tails were marked with different colours for identification purposes. A maximum of 4 rats were housed in a single polypropylene cage, to avoid overcrowding. All rats were given standard laboratory feed and water ad libitum.

\section{Ethical Clearance}

Clearance was obtained from the Institutional Animal Ethics Committee (IAEC number: IAEC/KMC/35/2015), and the experiment was conducted in accordance with the CPCSEA guidelines.

\section{Drugs}

Rivastigmine was used as standard therapy (dose was selected based on 2 previous studies), ${ }^{8,9)}$ while D-gal was used in the test groups. Normal saline was used in the control group. All drugs were administered once daily for a total duration of 8 weeks.

\section{Experimental Groups}

The different experimental groups were as follows (with 6 rats in each group): Group 1 (Control), normal saline (orally); Group 2 (Test group 1), D-gal 200 mg/kg/day (orally); Group 3 (Test group 2), D-gal 200 mg/kg/day (subcutaneously); Group 4 (Standard), rivastigmine 5 $\mathrm{mg} / \mathrm{kg} /$ day (orally).

\section{Test Procedures}

Two models were used to assess the effect of the test and standard drugs on learning and memory-Morris water maze test and passive avoidance test.

\section{Morris water maze ${ }^{5,10)}$}

All rats were accustomed to the water maze for a duration of 2 days before the training period, wherein they were allowed to freely swim. On the first day of acclimatization, no quadrants were marked, whereas on day 2, they were marked. Following this, the rats were given a training to identify a hidden platform (submerged about 2 $\mathrm{cm}$ below the water level in the north-west quadrant), in a pattern of 4 entries into the maze ( 1 from each quadrant) at an inter-entry interval of 1 minute each. The same was repeated thrice in a day for 4 days, separated by time intervals of 30 minutes each.

Following this training period, a baseline assessment was done, during which the swimming distance (the total distance that a rat travels before it reaches the hidden platform), swimming speed, north-west latency (the time taken by the rats to reach the north-west quadrant) and escape latency (the time taken for the rats to reach the hidden platform) were noted down from the automated software. The rats were then given the respective drugs, and again tested at 2 weeks, 4 weeks and 8 weeks. Training was done only once at the beginning of the experiment, as per protocol.

\section{Passive avoidance test ${ }^{5,11}$}

A step-through model of passive avoidance testing was followed in the study. A two-chambered box with a brightly-lit compartment and a darker (with a base that delivers a small electric shock) "punishing" compartment was utilized. On day 1 , the rats were acclimatized to the new environment. They were allowed to freely roam in the box. On day 2, a training session was conducted, wherein the rats were allowed to learn that the brightly-lit chamber is the safer option for them to stay in. On day 3, the actual test was conducted without the electric charge, to assess how many of the animals remembered that they had to stay in the brightly-lit compartment. Escape latency 
(the time taken for the rats to reach the dark chamber) and retention time (the total time spent by the rats in the brightly-lit chamber) were noted down manually at baseline, 2 weeks, 4 weeks and 8 weeks.

\section{Euthanasia}

After the experiment was concluded, all animals were humanely sacrificed by administering an overdose of ketamine, and then incinerated.

All values were tabulated and analyzed using IBM SPSS ver. 22.0 (IBM Co., Armonk, NY, USA). Mean \pm standard error of mean was used to express each parameter. Comparisons among the various experimental groups was performed using one-way analysis of variance (ANOVA), followed by post-hoc Tukey's test. The $p$ value of less than 0.05 was considered as statistically significant.

\section{RESULTS}

\section{Morris Water Maze}

\section{Swimming distance}

Swimming distance was captured from the automated software, based on the total distance that a rat travels before it reaches the hidden platform. Animals with im- paired memory and learning are bound to travel longer before they can arrive at the set platform.

As shown in Table 1 and Figure 1, the baseline distances were all comparable with each other, and no statistical differences were found ( $p>0.05)$. At 2 weeks, the swimming distance was found to be significantly reduced in groups $2(p=0.018)$ and $4(p=0.005)$, when compared

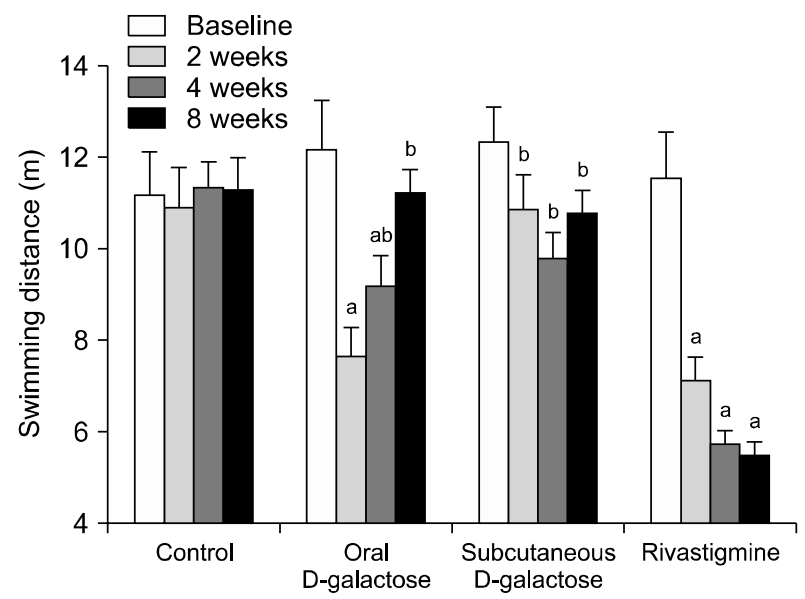

Fig. 1. Swimming distance $(\mathrm{m})$ assessed by Morris water maze test at different time points.

a denotes $p<0.05$ versus control group; $\mathrm{b}$ denotes $p<0.05$ versus standard group; $p$ value calculated using one-way ANOVA followed by Tukey's post-hoc test.

Table 1. Swimming distance assessed by Morris water maze test at different time points

\begin{tabular}{|c|c|c|c|c|c|}
\hline \multirow{2}{*}{\multicolumn{2}{|c|}{ Group }} & \multicolumn{4}{|c|}{ Swimming distance (m) } \\
\hline & & Baseline & 2 weeks & 4 weeks & 8 weeks \\
\hline 1 & Control & $11.17 \pm 0.93$ & $10.90 \pm 0.87$ & $11.33 \pm 0.56$ & $11.29 \pm 0.70$ \\
\hline 2 & Oral D-galactose & $12.16 \pm 1.07$ & $7.65 \pm 0.63^{\mathrm{a}}$ & $9.19 \pm 0.65^{\mathrm{ab}}$ & $11.23 \pm 0.49^{b}$ \\
\hline 3 & Subcutaneous D-galactose & $12.33 \pm 0.76$ & $10.86 \pm 0.75^{b}$ & $9.79 \pm 0.56^{b}$ & $10.77 \pm 0.50^{b}$ \\
\hline 4 & Rivastigmine & $11.54 \pm 0.99$ & $7.13 \pm 0.50^{\mathrm{a}}$ & $5.73 \pm 0.29^{\mathrm{a}}$ & $5.50 \pm 0.29^{a}$ \\
\hline
\end{tabular}

Values are presented as mean \pm standard error of mean.

${ }^{\mathrm{a}} p<0.05$ versus control group; ${ }^{\mathrm{b}} p<0.05$ versus standard group; $p$ value calculated using one-way ANOVA followed by Tukey's post-hoc test.

Table 2. Swimming speed assessed by Morris water maze test at different time points

\begin{tabular}{|c|c|c|c|c|c|}
\hline \multirow{2}{*}{\multicolumn{2}{|c|}{ Group }} & \multicolumn{4}{|c|}{ Swimming speed $(\mathrm{m} / \mathrm{s})$} \\
\hline & & Baseline & 2 weeks & 4 weeks & 8 weeks \\
\hline 1 & Control & $0.10 \pm 0.01$ & $0.11 \pm 0.01$ & $0.11 \pm 0.01$ & $0.11 \pm 0.00$ \\
\hline 2 & Oral D-galactose & $0.10 \pm 0.00$ & $0.17 \pm 0.01^{\mathrm{a}}$ & $0.19 \pm 0.01^{\mathrm{ab}}$ & $0.12 \pm 0.01^{b}$ \\
\hline 3 & Subcutaneous D-galactose & $0.11 \pm 0.00$ & $0.14 \pm 0.00^{\mathrm{ab}}$ & $0.15 \pm 0.01^{\mathrm{ab}}$ & $0.11 \pm 0.01^{b}$ \\
\hline 4 & Rivastigmine & $0.11 \pm 0.01$ & $0.19 \pm 0.01^{\mathrm{a}}$ & $0.23 \pm 0.01^{\mathrm{a}}$ & $0.30 \pm 0.01^{\mathrm{a}}$ \\
\hline
\end{tabular}

Values are presented as mean \pm standard error of mean.

a $p<0.05$ versus control group; ${ }^{\mathrm{b}} p<0.05$ versus standard group; $p$ value calculated using one-way ANOVA followed by Tukey's post-hoc test. 
to control. At 4 weeks, the distances travelled by rats in groups $2(p=0.045)$ and $4(p<0.001)$ were again significantly reduced when compared to that of the control group. At 8 weeks, only group $4(p<0.001)$ showed statistically significant reduction in swimming distance when compared against control.

\section{Swimming speed}

Swimming speeds were captured from the automated software till the rats reached the hidden platform. Animals with impaired memory and learning are bound to travel slower.

As shown in Table 2 and Figure 2, the baseline speeds were all comparable with each other, and no statistical differences were found ( $p>0.05)$. At 2 weeks, the swimming speed was found to be significantly increased in groups $2(p<0.001), 3(p=0.036)$ and $4(p<0.001)$, when compared to control. At 4 weeks, the speeds of the rats in groups $2(p<0.001), 3(p=0.019)$ and $4(p<0.001)$ were

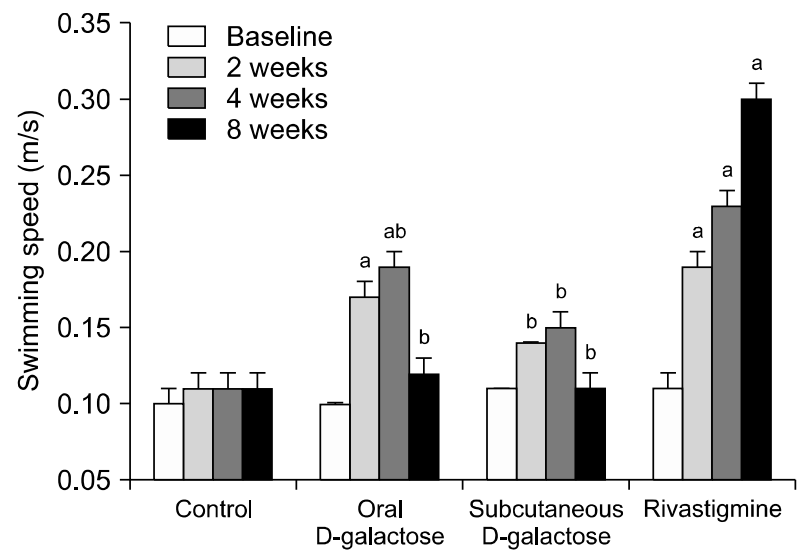

Fig. 2. Swimming speed $(\mathrm{m} / \mathrm{s})$ assessed by Morris water maze test at different time points.

a denotes $p<0.05$ versus control group; $\mathrm{b}$ denotes $p<0.05$ versus standard group; $p$ value calculated using one-way ANOVA followed by Tukey's post-hoc test. again significantly increased when compared to that of the control group. At 8 weeks, only group $4(p<0.001)$ showed statistically significant rise in speed, when compared against control.

\section{Escape latency}

Escape latency was calculated by taking the time taken for the rats to reach the hidden platform. Animals with impaired memory and learning are bound to travel longer before they can arrive at the set platform, thereby taking more time to find the platform.

As shown in Table 3 and Figure 3, the baseline escape latency times were all comparable with each other, and no statistical differences were found $(p>0.05)$. At 2 weeks, the escape latency was found to be significantly lower in groups $2(p<0.001), 3(p<0.001)$ and $4(p$ $<0.001)$, when compared to control. At 4 weeks, the time taken by the rats in groups $2(p<0.001), 3(p<0.001)$ and $4(p<0.001)$ was significantly reduced when compared

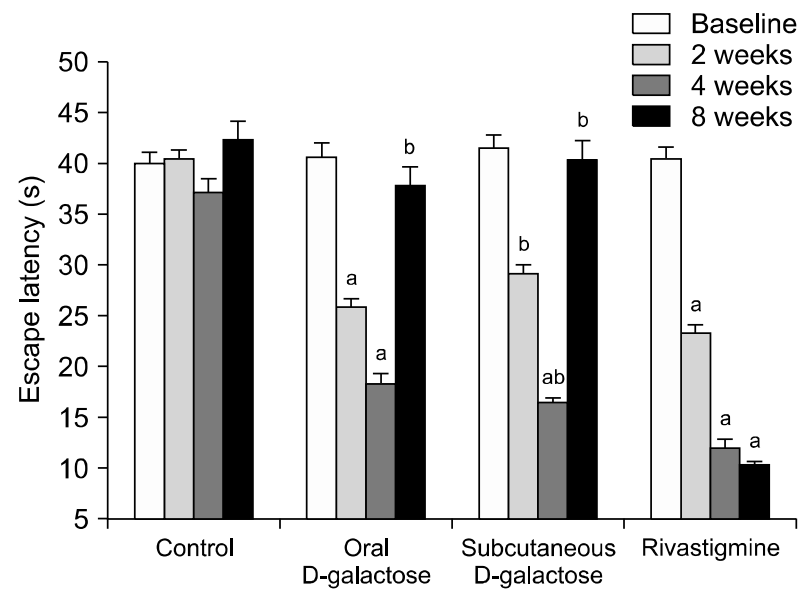

Fig. 3. Escape latency (s) assessed by Morris water maze test at different time points.

a denotes $p<0.05$ versus control group; b denotes $p<0.05$ versus standard group; $p$ value calculated using one-way ANOVA followed by Tukey's post-hoc test.

Table 3. Escape latency assessed by Morris water maze test at different time points

\begin{tabular}{|c|c|c|c|c|c|}
\hline & \multirow{2}{*}{ Group } & \multicolumn{4}{|c|}{ Escape latency (s) } \\
\hline & & Baseline & 2 weeks & 4 weeks & 8 weeks \\
\hline 1 & Control & $40.00 \pm 1.06$ & $40.5 \pm 0.76$ & $37.17 \pm 1.17$ & $42.33 \pm 1.38$ \\
\hline 2 & Oral D-galactose & $40.67 \pm 1.33$ & $25.83 \pm 0.87^{\mathrm{a}}$ & $18.33 \pm 1.31^{\mathrm{ab}}$ & $37.83 \pm 0.87^{b}$ \\
\hline 3 & Subcutaneous D-galactose & $41.50 \pm 1.26$ & $29.17 \pm 0.79^{\mathrm{ab}}$ & $16.50 \pm 0.43^{\mathrm{ab}}$ & $40.33 \pm 1.28^{b}$ \\
\hline 4 & Rivastigmine & $40.50 \pm 1.06$ & $23.33 \pm 0.71^{\mathrm{a}}$ & $12.00 \pm 0.86^{\mathrm{a}}$ & $10.33 \pm 1.15^{\mathrm{a}}$ \\
\hline
\end{tabular}

Values are presented as mean \pm standard error of mean.

${ }^{a} p<0.05$ versus control group; ${ }^{\mathrm{b}} p<0.05$ versus standard group; $p$ value calculated using one-way ANOVA followed by Tukey's post-hoc test. 
to that of the control group. At 8 weeks, only group 4 ( $p$ $<0.001)$ showed statistically significant fall in escape latency, when compared against control.

\section{North-west latency}

North-west latency was calculated by taking the time taken by the rats to reach the quadrant (north-west) that contained the hidden platform. Animals with impaired memory and learning are bound to take a longer time to arrive at the quadrant with the set platform.

As shown in Table 4 and Figure 4, the baseline north-west latency times were all comparable with each other, and no statistical differences were found ( $p>0.05)$. At 2 weeks, the north-west latency was found to be significantly lower in groups $2(p<0.001), 3(p<0.001)$ and $4(p=0.012)$, when compared to control. At 4 weeks, the time taken by the rats in groups $2(p<0.001), 3(p<$ $0.001)$ and $4(p<0.001)$ was significantly reduced when compared to that of the control group. At 8 weeks, only group $4(p<0.001)$ showed statistically significant fall in escape latency, when compared against control.

\section{Passive Avoidance Test}

\section{Escape latency}

Escape latency was calculated by taking the time taken for the rats to reach the dark chamber. Animals with impaired memory and learning are bound to travel quicker into the dark chamber.

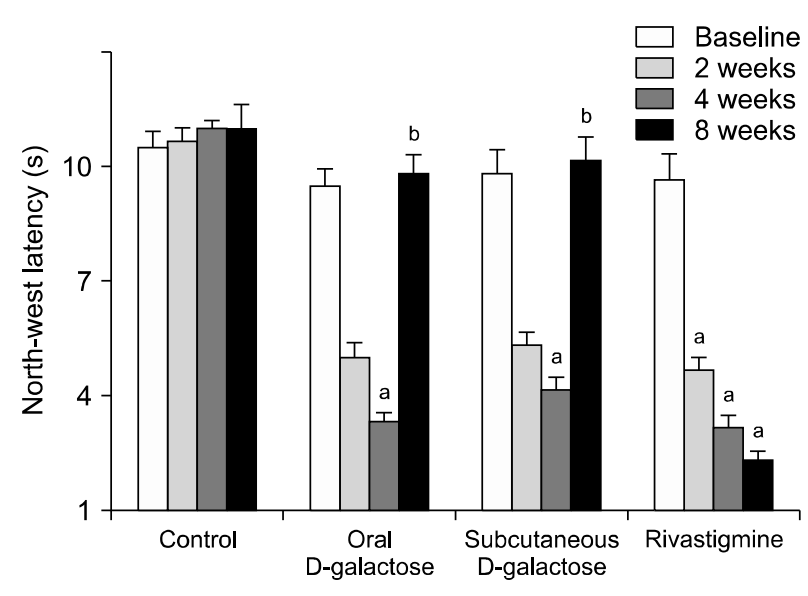

Fig. 4. North-west latency (s) assessed by Morris water maze test at different time points.

a denotes $p<0.05$ versus control group; b denotes $p<0.05$ versus standard group; $p$ value calculated using one-way ANOVA followed by Tukey's post-hoc test.

Table 4. North-west latency assessed by Morris water maze test at different time points

\begin{tabular}{|c|c|c|c|c|c|}
\hline & \multirow{2}{*}{ Group } & \multicolumn{4}{|c|}{ North-west latency (s) } \\
\hline & & Baseline & 2 weeks & 4 weeks & 8 weeks \\
\hline 1 & Control & $10.50 \pm 0.43$ & $10.67 \pm 0.67$ & $11.00 \pm 0.52$ & $11.00 \pm 0.57$ \\
\hline 2 & Oral D-galactose & $9.50 \pm 0.43$ & $5.00 \pm 0.37^{\mathrm{a}}$ & $3.33 \pm 0.21^{\mathrm{a}}$ & $9.83 \pm 0.61^{b}$ \\
\hline 3 & Subcutaneous D-galactose & $9.83 \pm 0.60$ & $5.33 \pm 0.33^{\mathrm{a}}$ & $4.17 \pm 0.31^{\mathrm{a}}$ & $10.17 \pm 0.65^{b}$ \\
\hline 4 & Rivastigmine & $9.67 \pm 0.67$ & $4.67 \pm 0.33^{a}$ & $3.17 \pm 0.31^{\mathrm{a}}$ & $2.33 \pm 0.21^{\mathrm{a}}$ \\
\hline
\end{tabular}

Values are presented as mean \pm standard error of mean.

${ }^{\mathrm{a}} p<0.05$ versus control group; ${ }^{\mathrm{b}} p<0.05$ versus standard group; $p$ value calculated using one-way ANOVA followed by Tukey's post-hoc test.

Table 5. Escape latency assessed by passive avoidance test at different time points

\begin{tabular}{|c|c|c|c|c|c|}
\hline & \multirow{2}{*}{ Group } & \multicolumn{4}{|c|}{ Escape latency (s) } \\
\hline & & Baseline & 2 weeks & 4 weeks & 8 weeks \\
\hline 1 & Control & $15.56 \pm 0.53$ & $15.35 \pm 1.11$ & $15.98 \pm 1.05$ & $15.45 \pm 0.96$ \\
\hline 2 & Oral D-galactose & $15.34 \pm 0.45$ & $39.81 \pm 2.50^{\mathrm{a}}$ & $36.29 \pm 2.73^{\mathrm{ab}}$ & $23.63 \pm 2.41^{b}$ \\
\hline 3 & Subcutaneous D-galactose & $15.73 \pm 0.54$ & $22.54 \pm 2.13^{b}$ & $22.17 \pm 2.07^{\mathrm{b}}$ & $31.98 \pm 3.77^{\mathrm{b}}$ \\
\hline 4 & Rivastigmine & $15.02 \pm 0.41$ & $37.28 \pm 4.11^{\mathrm{a}}$ & $53.16 \pm 4.94^{\mathrm{a}}$ & $86.32 \pm 11.38^{\mathrm{a}}$ \\
\hline
\end{tabular}

Values are presented as mean \pm standard error of mean.

${ }^{\mathrm{a}} p<0.05$ versus control group; ${ }^{\mathrm{b}} p<0.05$ versus standard group; $p$ value calculated using one-way ANOVA followed by Tukey's post-hoc test. 
As shown in Table 5 and Figure 5, the baseline escape latency times were all comparable with each other, and no statistical differences were found $(p>0.05)$. At 2 weeks, the escape latency was found to be significantly higher in groups $2(p<0.001)$ and $4(p<0.001)$, when compared to control. Also, at 4 weeks, the time taken by the rats in groups $2(p=0.001)$ and $4(p<0.001)$ was significantly higher when compared to that of the control group. At 8 weeks, only group $4(p<0.001)$ showed statistically significant rise in escape latency, when compared against control.

\section{Retention time}

Retention time was calculated by taking the total time spent by the rats in the brightly-lit chamber. Animals with impaired memory and learning are bound to travel quicker into the dark chamber, and thereby have shorter retention times.

As shown in Table 6 and Figure 6 , the baseline re-

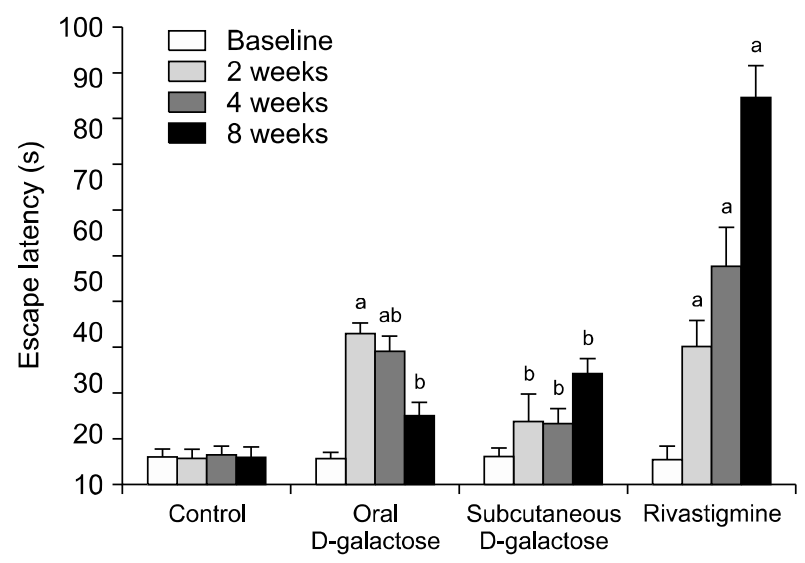

Fig. 5. Escape latency (s) assessed by passive avoidance test at different time points.

a denotes $p<0.05$ versus control group; $\mathrm{b}$ denotes $p<0.05$ versus standard group; $p$ value calculated using one-way ANOVA followed by Tukey's post-hoc test. tention times were all comparable with each other, and no statistical differences were found $(p>0.05)$. At 2 weeks, the retention time was found to be significantly higher in groups $2(p<0.001), 3(p<0.001)$ and $4(p$ $<0.001$ ), when compared to control. Again, at 4 weeks, the time spent in the bright chamber by the rats in groups $2(p=0.005), 3(p=0.017)$ and $4(p<0.001)$ was significantly higher when compared to that of the control group. Similarly, at 8 weeks, only group $4(p<0.001)$ showed statistically significant rise in retention time, when compared against control.

To summarize, our results have shown that oral D-gal $200 \mathrm{mg} / \mathrm{kg} /$ day had beneficial effects on memory and learning during the short-term administration period, whereas the same benefit was lost when the rats were dosed for longer periods. Subcutaneous D-gal 200 $\mathrm{mg} / \mathrm{kg} /$ day also showed a positive trend in all parameters except for swimming distance (Morris water maze model) and escape latency (passive avoidance model), when as-

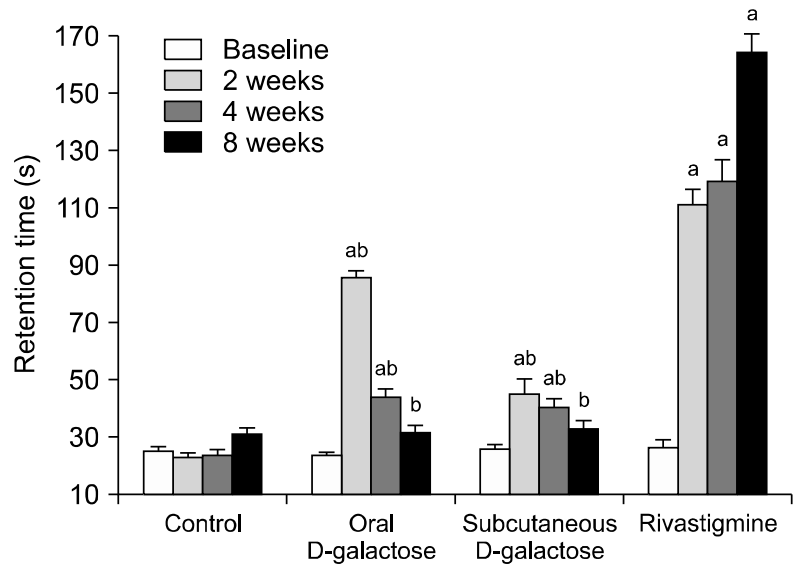

Fig. 6. Retention time (s) assessed by passive avoidance test at different time points.

a denotes $p<0.05$ versus control group; $\mathrm{b}$ denotes $p<0.05$ versus standard group; $p$ value calculated using one-way ANOVA followed by Tukey's post-hoc test.

Table 6. Retention time assessed by passive avoidance test at different time points

\begin{tabular}{|c|c|c|c|c|c|}
\hline \multirow{2}{*}{\multicolumn{2}{|c|}{ Group }} & \multicolumn{4}{|c|}{ Retention time (s) } \\
\hline & & Baseline & 2 weeks & 4 weeks & 8 weeks \\
\hline 1 & Control & $25.13 \pm 1.46$ & $23.05 \pm 1.56$ & $20.67 \pm 0.88$ & $21.99 \pm 1.98$ \\
\hline 2 & Oral D-galactose & $23.76 \pm 0.97$ & $85.87 \pm 2.08^{\mathrm{ab}}$ & $44.10 \pm 2.91^{\mathrm{ab}}$ & $31.72 \pm 2.49^{b}$ \\
\hline 3 & Subcutaneous D-galactose & $25.96 \pm 1.47$ & $45.20 \pm 5.21^{\mathrm{ab}}$ & $44.10 \pm 2.91^{\mathrm{ab}}$ & $33.11 \pm 2.69^{b}$ \\
\hline 4 & Rivastigmine & $26.57 \pm 2.57$ & $111.41 \pm 5.03^{\mathrm{a}}$ & $119.51 \pm 7.51^{\mathrm{a}}$ & $164.62 \pm 6.06^{\mathrm{a}}$ \\
\hline
\end{tabular}

Values are presented as mean \pm standard error of mean.

${ }^{a} p<0.05$ versus control group; ${ }^{\mathrm{b}} p<0.05$ versus standard group; $p$ value calculated using one-way ANOVA followed by Tukey's post-hoc test. 
sessed in the acute period. Further, rivastigmine (used as the standard drug) showed beneficial effects on memory and learning in all the measured parameters, thereby reinforcing the drug as a standard comparator for models of learning and memory.

\section{DISCUSSION}

Our study revealed that acute administration of D-gal showed promising results on learning and memory at the end of 2 weeks and 4 weeks, when compared to control. However, by the end of 8 weeks (chronic administration), the results were no longer significant. In fact, they were comparable with the control or baseline values. There was no further worsening of the test results beyond the control values, probably because the duration of 2 months was not enough. Had the project been extended beyond the current duration of 2 months, worsening compared to control group might have been seen.

On careful examination of results at 2 weeks, it shows that oral D-gal given at $200 \mathrm{mg} / \mathrm{kg} /$ day showed better improvement in memory and learning when compared to 200 mg/kg/day subcutaneous D-gal. A similar study was done by Salkovic-Petrisic et al. ${ }^{5)}$ the results of which show that oral D-gal improved memory and learning when compared to parenteral D-gal, when used in streptozotocin-treated rats. However, when used alone, D-gal did not show significant results, the reason for which was not explained. Also, in this study, the effects were chiefly compared using glucose and galactose levels in the blood and CSF, and not behavioural studies. ${ }^{5)}$

Oral administration of D-gal probably increases the levels of incretins like glucagon like peptide-1 (GLP1) and glucose dependent insulinotropic polypeptide, which promote insulin secretion. ${ }^{12)}$ GLP1 analogues have demonstrated improvement in learning and memory plus have also shown to reduce levels of hyperphosphorylated tau and total tau levels, ${ }^{13)}$ which may not be evident with parenteral routes. In our opinion, this difference might also be attributed to variations in drug bioavailability between the two routes.

However, at 8 weeks, there was deterioration in the learning ability and memory when D-gal was given through both oral and parenteral routes, compared to the results at 2 weeks and at 4 weeks, and the results were comparable with those of the control group. The mecha- nism behind this difference at time points was not analyzed, and it could be plainly due to resistance to D-gal. The duration of the present study might have been too short to have shown any significant deterioration compared to the control group, as was seen in previous studies. In another study, D-gal induced memory loss and learning impairment on chronic use, which has been attributed to generation of free radicals, resulting in impairment of neurogenesis and ultimately, neurodegeneration. ${ }^{14-16)}$ Caspase-mediated apoptosis, which resulted in degeneration of neurons, was also seen in these studies.

A study done by Wei et al. ${ }^{17)}$ using Morris water maze model and object recognition test in 2005 using D-gal showed that mice spent less time swimming in the target quadrant and increased escape latencies. The authors had used three subcutaneous doses for a period of 8 weeks; - 50, 100, and $200 \mathrm{mg} / \mathrm{kg} /$ day. D-gal impaired memory and affected cells in a dose dependent manner (50-100 mg/kg), bringing about changes of natural ageing. ${ }^{17)}$

Another study done by Haider et al. ${ }^{18)}$ reported that short-term (1 week) high dose $(300 \mathrm{mg} / \mathrm{kg} /$ day intraperitoneally) administration of D-gal showed anxiogenic and depressogenic behavior. It also altered memory functions. As mentioned in the aforementioned studies, even this was attributed to free radical-mediated damage. Superoxide dismutase activity and lipid peroxidation activity were increased significantly and the activities of glutathione peroxidase and catalase were decreased. ${ }^{18)}$ This is probably because a very high dose was used in this study as opposed to our study, wherein lower doses were used. In addition, in the present study, the routes of drug administration were different-oral and subcutaneous.

Our study showed a definite initial improvement followed by deterioration of learning and memory in both the models tested. The initial improvement could be due to a rise in the incretin levels, as mentioned before. We attribute the deterioration to free radical-mediated neuronal damage, as suggested by earlier studies.

This study has some limitations. Firstly, only one dose each of oral and subcutaneous formulations was considered in our study. So, we do not know whether the effects are dose dependent. Ideally, multiple doses should have been used. Secondly, only one animal species was utilized, and only the male gender was included. This was to remove the influence of hormonal changes in female rats. However, showing the beneficial effects of galactose on 
both sexes of rats would have been ideal. Thirdly, tendency to show declined on chronic administration was observed. Ideally, the study should have been continued further to see whether the deterioration was progressive and worsening compared to control was seen. Fourthly, a high dose of rivastigmine was used in the present study, taking into account the dose used in two previous studies. And the mechanism by which D-gal improved/impaired memory and learning in the current study was not studied. Instead, the mechanisms from previous studies were considered. Lastly, neurochemical and neuro-histological assays were not performed.

In conclusion, both oral and subcutaneous D-gal showed significant beneficial effects on learning and memory, when its acute effects are taken into account. On chronic administration, beneficial effects were lost, and were comparable with the control or baseline values. On further chronic administration, there might have been complete worsening, as a tendency of decline was observed in the present study.

The effects of D-gal seem to vary with changes in the duration of therapy. Although it is routinely used to induce accelerated aging in rodents, there are studies that imply insufficient evidence for the same. Further studies may be required to ascertain the same, and also to confirm the beneficial effects produced with short-term use of the drug.

\section{REFERENCES}

1. Chen CF, Lang SY, Zuo PP, Yang N, Wang XQ, Xia C. Effects of D-galactose on the expression of hippocampal peripheral-type benzodiazepine receptor and spatial memory performances in rats. Psychoneuroendocrinology 2006;31:805811.

2. Gropper SS, Weese JO, West PA, Gross KC. Free galactose content of fresh fruits and strained fruit and vegetable baby foods: more foods to consider for the galactose-restricted diet. J Am Diet Assoc 2000;100:573-575.

3. Parameshwaran K, Irwin MH, Steliou K, Pinkert CA. D-galactose effectiveness in modeling aging and therapeutic antioxidant treatment in mice. Rejuvenation Res 2010;13: 729-735.

4. Budni J, Pacheco R, da Silva S, Garcez ML, Mina F, Bellettini-Santos $\mathrm{T}$, et al. Oral administration of d-galactose induces cognitive impairments and oxidative damage in rats. Behav Brain Res 2016;302:35-43.

5. Salkovic-Petrisic M, Osmanovic-Barilar J, Knezovic A, Hoyer S, Mosetter K, Reutter W. Long-term oral galactose treatment prevents cognitive deficits in male Wistar rats treated intracerebroventricularly with streptozotocin. Neuropharmacology 2014;77:68-80.

6. Cardoso A, Magano S, Marrana F, Andrade JP. D-galactose high-dose administration failed to induce accelerated aging changes in neurogenesis, anxiety, and spatial memory on young male Wistar rats. Rejuvenation Res 2015;18:497-507.

7. Bejar C, Wang RH, Weinstock M. Effect of rivastigmine on scopolamine-induced memory impairment in rats. Eur J Pharmacol 1999;383:231-240.

8. Thippeswamy AH, Rafiq M, Viswantha GL, Kavya KJ, Anturlikar SD, Patki PS. Evaluation of Bacopa monniera for its synergistic activity with rivastigmine in reversing aluminum-induced memory loss and learning deficit in rats. J Acupunct Meridian Stud 2013;6:208-213.

9. Agrawal R, Tyagi E, Saxena G, Nath C. Cholinergic influence on memory stages: A study on scopolamine amnesic mice. Indian J Pharmacol 2009;41:192-196.

10. Pritchett D, Taylor AM, Barkus C, Engle SJ, Brandon NJ, Sharp $\mathrm{T}$, et al. Searching for cognitive enhancement in the Morris water maze: better and worse performance in D-amino acid oxidase knockout (Dao(-/-)) mice. Eur / Neurosci 2016;43: 979-989.

11. Gutherz SB, Kulick CV, Soper C, Kondratyev A, Gale K, Forcelli PA. Brief postnatal exposure to phenobarbital impairs passive avoidance learning and sensorimotor gating in rats. Epilepsy Behav 2014;37:265-269.

12. Phillips LK, Prins JB. Update on incretin hormones. Ann $N Y$ Acad Sci 2011;1243:E55-E74.

13. Li L, Zhang ZF, Holscher C, Gao C, Jiang YH, Liu YZ. (VaP) glucagon-like peptide-1 prevents tau hyperphosphorylation, impairment of spatial learning and ultra-structural cellular damage induced by streptozotocin in rat brains. Eur J Pharmacol 2012;674:280-286.

14. Gao J, Zhou R, You X, Luo F, He H, Chang X, et al. Salidroside suppresses inflammation in a D-galactose-induced rat model of Alzheimer's disease via SIRT1/NF- $\kappa$ B pathway. Metab Brain Dis 2016;31:771-778.

15. Ullah F, Ali T, Ullah N, Kim MO. Caffeine prevents d-galactose-induced cognitive deficits, oxidative stress, neuroinflammation and neurodegeneration in the adult rat brain. Neurochem Int 2015;90:114-124.

16. Cui X, Zuo $\mathrm{P}$, Zhang Q, Li X, Hu Y, Long J, et al. Chronic systemic D-galactose exposure induces memory loss, neurodegeneration, and oxidative damage in mice: protective effects of R-alpha-lipoic acid. J Neurosci Res 2006;84:647-654.

17. Wei H, Li L, Song Q, Ai H, Chu J, Li W. Behavioural study of the D-galactose induced aging model in C57BL/6J mice. Behav Brain Res 2005;157:245-251.

18. Haider S, Liaquat L, Shahzad S, Sadir S, Madiha S, Batool Z, et al. A high dose of short term exogenous D-galactose administration in young male rats produces symptoms simulating the natural aging process. Life Sci 2015;124:110-119. 